Acta Technologica Agriculturae 3

Nitra, Slovaca Universitas Agriculturae Nitriae, 2019, pp. 99-103

\title{
THEORETICAL RESEARCH OF THE DESIGN AND TECHNOLOGICAL PARAMETERS OF A DEVICE FOR LIFTING OF DEEP-SEATED TABLE ROOT CROPS
}

\author{
Volodymyr BULGAKOV ${ }^{1}$, Semjons IVANOVS ${ }^{2 *}$, Igor SAFCHENKO ${ }^{3}$, Andrii BORIS ${ }^{3}$, Petro RYCHLIVSKYJ ${ }^{3}$ \\ ${ }^{1}$ National University of Life and Environmental Sciences of Ukraine, Ukraine \\ ${ }^{2}$ Latvia University of Life Sciences and Technologies, Latvia \\ ${ }^{3}$ National Scientific Center "Institute for Agricultural Engineering and Electrification", Ukraine
}

\begin{abstract}
Due to the high energy intensity of lifting of deep-seated table root crops, their growth develops mainly in light sandy-loam soils, in which it is possible to transfer a heap of root crops to the separating devices in order to facilitate the qualitative separation. Therefore, issue of lifting of deep-seated table root crops at minimal energy consumption and labour costs is an important scientific and practical task, which would allow expansion of cultivation of deep-seated table root vegetables to heavy soils. Research was conducted by means of a theoretical method utilizing elements of theoretical mechanics with subsequent processing of results by means of PC. Mathematical model and resulting energy cost dependences were constructed on the basis of the device parameters for soil loosening and lifting of deep-seated table root crops. Refined mathematical model of the process of lifting of deep-seated root crops made it possible to find out scientific and technical preconditions for the development of lifting devices with minimal energy consumption.
\end{abstract}

Keywords: root crops; lifting devices; soil, energy consumption; mathematical model

Table root crops represent valuable group of products and their cultivation is an important branch of agriculture (Chloupek, 2004; Bulgakov et al., 2015). However, cultivation and especially harvesting of the root crops is generally a labour-consuming and expensive process that largely determines the prime cost of the product (Anar et al., 2019; Bulgakov et al., 2016). Considering the stage of lifting of deepseated root crops, several scientific and production issues arise in terms of increased energy intensity of lifting of these crops in heavy soils, and low process efficiency (Pavlocky, 2015; Bulgakov et al., 2013; Vilde and Rucins, 2012). There used to be a tradition of digging out deep-seated table root crops with diggers and their manual pickup. Energy costs reached $7 \mathrm{~kW}$ per 1 row and overall efficiency of the pickup process did not exceed $0.2-0.3 \mathrm{ha} \cdot \mathrm{h}^{-1}$ in such case. Taking into account the aforementioned circumstances, mass cultivation of the deep-seated table root crops is possible only in the light sandy-loam soils, in which it is possible to transfer the heap of the root crops to the separating devices in order to carry out high-quality separation. Therefore, issue of lifting of deep-seated table root crops with minimal energy consumption and labour costs is an important scientific and practical task that allows for expansion of the area of growing deep-seated table root crops in heavy soils.

Solution to this issue is proposed as follows. Technological process of lifting of root crops was divided into two stages: loosening of a soil layer using special soil-tillage device and pickup of this layer using a digger with subsequent separation (Pavlov et al., 1975). As the preliminary tests of the machine operation according to this technological scheme showed, separation of the heap of root crops becomes efficient also in heavy soils in this case. Furthermore, an important task is to reduce the energy consumption of the devices (Rucins and Vilde, 2005; Gao et al., 2013; Formato et al., 2017; Aulin et al., 2018). Therefore, goal is to investigate the soil loosening process while lifting the root crops and substantiate the device parameters for its implementation.

\section{Material and methods}

To implement the soil loosening process, a new device has been developed (Fig. 1).

During the device movement, toothed rotors, rotating on axes, penetrate the soil to the depth of the deep-seated roots simultaneously with the ploughshare. Rotor teeth concentrate the forces of interaction on the soil layer, resulting in soil crumbling together with partial lifting of root crops. Due to the selected rotation direction of the working body relative to the movement direction, process of soil release occurs predominantly as a result of soil tensile stress and ensures minimal energy consumption. Loosened part of the soil is additionally deformed on the ploughshare back side and root crops with the soil remnants are transferred to the separating conveyor for final cleaning. Therefore, design and geometry of the proposed device provide crumbling of soil around the root crops to the depth of their bedding,

Contact address: Semjons Ivanovs, Latvia University of Life Sciences and Technologies, 2 Liela str., Jelgava, Latvia, e-mail: semjons@apollo.lv 

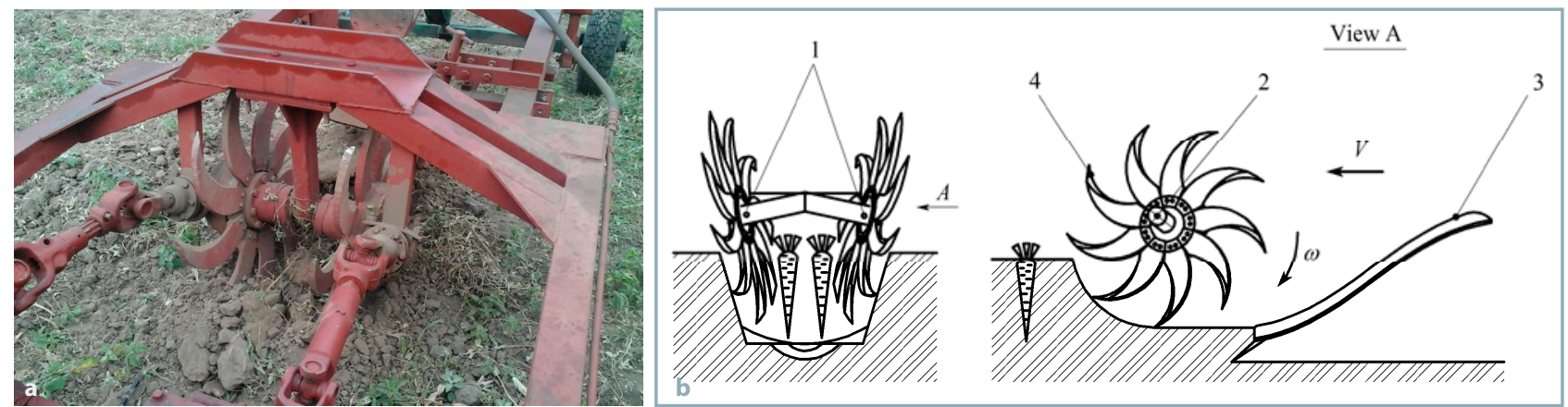

Fig. 1 Device for lifting of deep-seated table root crops

a) general view of the device; b) structural scheme: 1 - toothed rotors, 2 - rotor axle, 3 - ploughshare, 4 - rotor teeth

reducing the energy costs for their lifting and cleaning from soil.

In order to assess the energy efficiency of work of toothed rotors in the process of lifting of deep-seated table root crops, a scheme of a mathematical model of its functioning will be constructed. For this purpose, fixed system of Cartesian coordinates $\mathrm{XOY}$ and movable $\mathrm{X}_{1} \mathrm{O}_{1} Y_{1}$ connected with the centre of the rotor $O_{1}$, which returns at an angle $\varphi$ together with the rotor (Fig. 1), will be considered.

Let the aggregate move in a straight line and uniformly at speed $V$. Simultaneously, it is rotating around its axis according to the law $\varphi=\omega t$, where $\omega=$ constant (angular velocity of the rotor).

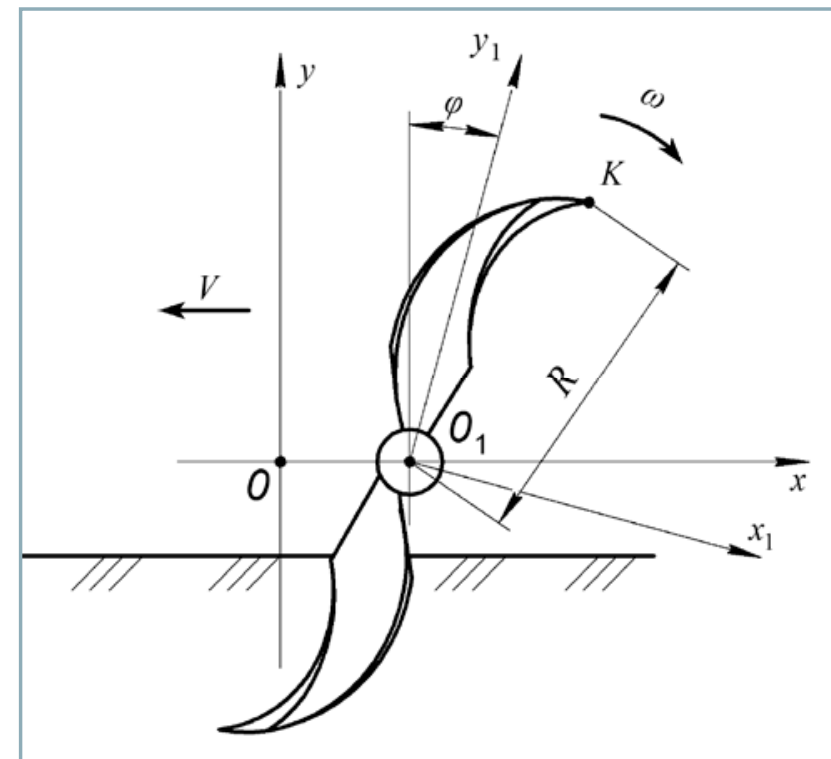

Fig. 2 Equivalent scheme of the interaction between rotor and soil layer

Let us consider the movement of the tooth tip (point $K$ in Fig. 2). It is easy to see that the point $K$ at tooth top (located at a distance $R$ from the rotation centre $O_{1}$ ) describes the cycloid, which, in turn, is described by well-known formulas (Fox and Pratt, 1982):

$$
\begin{aligned}
& x= \pm R \sin \omega t+V \\
& y= \pm R(1-\cos \omega t)
\end{aligned}
$$

In order to determine the energy intensity, interaction of rotor teeth with soil layer must be taken into account. To determine the energy costs, dependencies of consumed power on time will be in a form:

$$
N(t)=M(t) \frac{30 \cdot \omega}{\pi}
$$

where:

$M(t) \quad$ - torque on the rotor shaft $(\mathrm{N} \cdot \mathrm{m})$

Unknown component $M(t)$ can be defined from the expression:

$$
S(t)=S(t) \cdot P(t) \cdot h(t)
$$

where:

$S(t)$ - dynamic cross-sectional area of interaction between teeth and soil layer $\left(\mathrm{m}^{2}\right)$

$P(t) \quad$ - specific forces of soil deformation $\left(\mathrm{N} \cdot \mathrm{m}^{2}\right)$

$h(t) \quad-$ arm of an equivalent concentrated soil reaction acting upon the tooth $(\mathrm{m})$

Let the tooth interact with a soil layer of thickness equal to - $a$ (Fig. 3). In case when a tooth penetrates the soil and has previously removed a layer of soil, there occurs a shape confined by lines 1 and 2. Considering the first assumption, it is assumed that the tooth has a straight shape, and interaction area of tooth with soil layer will be as depicted in Fig. 2:

$$
S(t)=b k
$$

where:

$$
\begin{array}{ll}
b & - \text { tooth width }(\mathrm{m}) \\
k & - \text { tooth penetration degree through the soil }(\mathrm{m})
\end{array}
$$

Value $k$ expresses the distance between the two points on a plane according to the known formulas from the course of analytic geometry (Fig. 4):

$$
M_{1} M_{2}=k=\sqrt{\left(x_{M_{1}}-x_{M_{2}}\right)^{2}+\left(y_{M_{1}}-y_{M_{2}}\right)^{2}}
$$

Since the analytical expression of the coordinates of point $M_{2}$ is related to the solution of transcendental equations and is not expressed by elementary functions, 

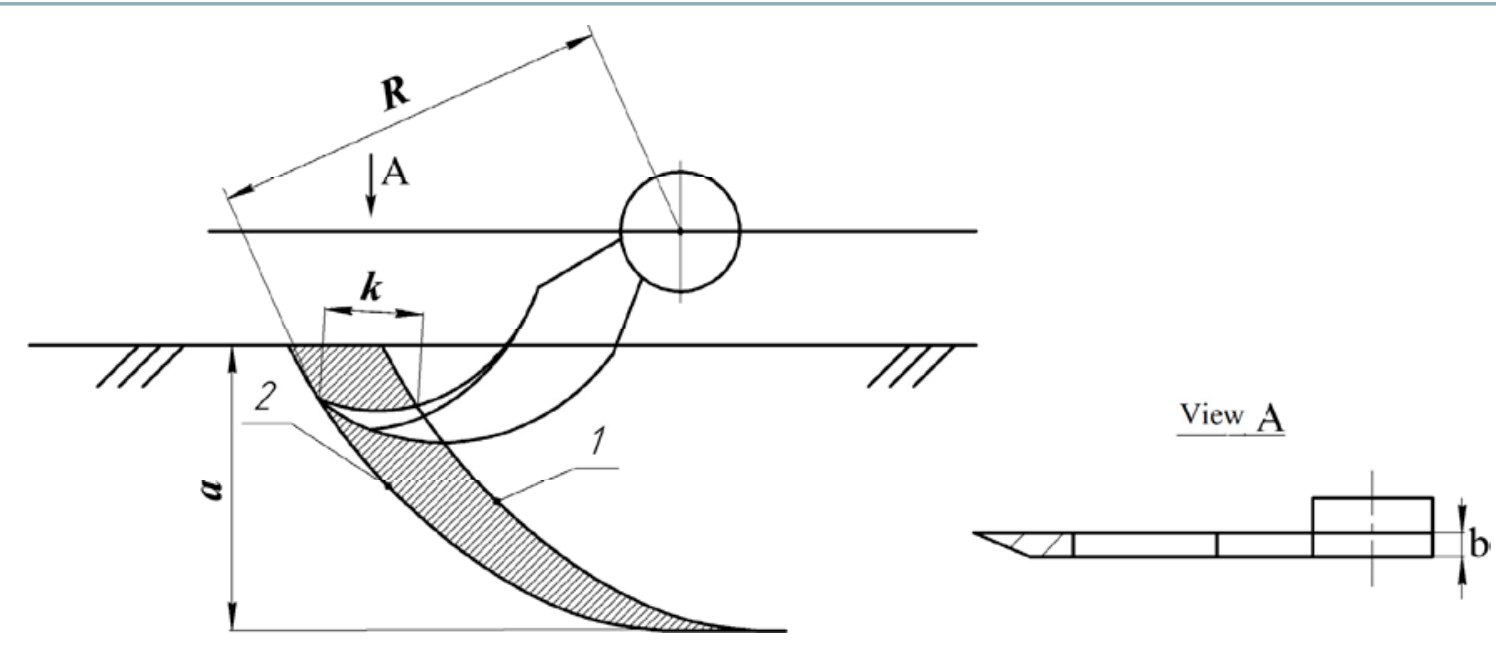

Fig. 3 Scheme for determination of rotor teeth interaction area with a soil layer

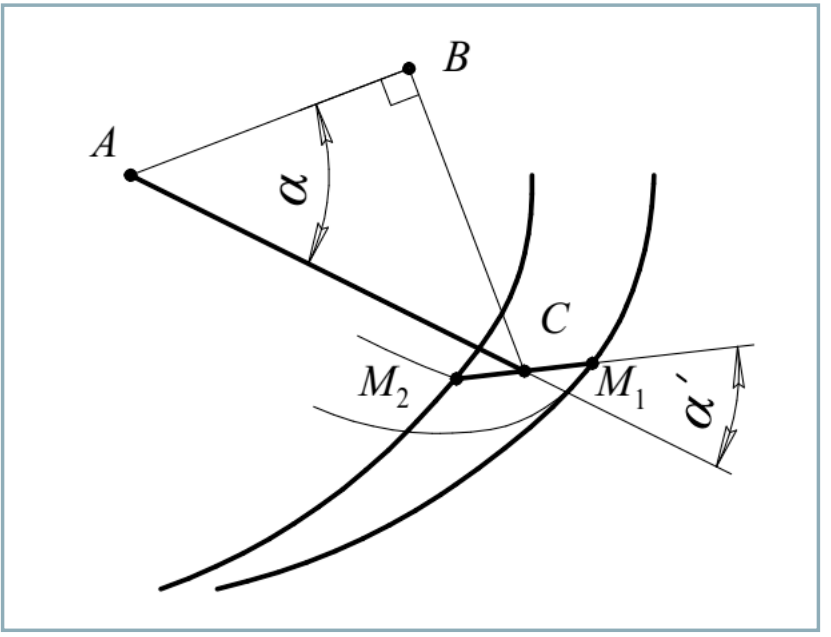

Fig. 4 Scheme for determination of soil reaction force arm upon the tooth

these will be defined by means of a numerical method using the KOMPAS 3D program.

Furthermore, it is necessary to find the arm of equivalent concentrated soil reaction acting upon the tooth. It is evident from Fig. 4 that the $\operatorname{arm} h$ is equal to segment $A B$ and it is parallel to segment $M_{1} M_{2}$. $A C$ is a segment connecting the centre of the rotor to the point of application of the concentrated soil reaction; subsequently, segment $A B$ is the arm of indicated reaction. Angle $\alpha$ represents the angle between segment $A C$ and arm $A B$.

Value of segment $A B$ is determined from the expression:

$$
A B=\cos \alpha \cdot A C
$$

Since the segments $A B$ and $M_{1} M_{2}$ are parallel, it is possible to anticipate that angle $\alpha$ is equal to angle $\alpha^{\prime}$ (Fig. 4) and can be found as an angle of two directing vectors of the straight lines containing segments $A C$ and $M_{1} M_{2}$ :

$$
\alpha=\arccos \left(\frac{x_{a c} \cdot x_{m 1 m 2}+y_{a c} \cdot y_{m 1 m 2}}{\sqrt{x_{a c}^{2}+y_{a c}^{2}} \cdot \sqrt{x_{m 1 m 2}{ }^{2}+y_{m 1 m 2}^{2}}}\right)
$$

where:

$x_{a c}, y_{a c}$ and $x_{m 1 m 2}, y_{m 1 m 2}$ - the coordinates of the directing vectors of straight segments $A C$ and $M_{1} M_{2}$, respectively

To find out the coordinates of these vectors, it is necessary to find the coordinates of point $C$ at first by means of the following formulas:

$$
\begin{aligned}
& x_{c}=x_{m 1}+\left(\frac{x_{m 2}-x_{m 1}}{2}\right) \\
& y_{c}=y_{m 1}+\left(\frac{y_{m 2}-y_{m 1}}{2}\right)
\end{aligned}
$$

The coordinates of directing vector of straight line containing segment $A C$ will then be equal to:

$$
\begin{gathered}
x_{a c}=x_{c}-V \cdot t \\
y_{a c}=y_{c}-R
\end{gathered}
$$

Considering Eqs. 9 and 10, it is possible to re-write as follows:

$$
\begin{gathered}
x_{a c}=\left(x_{m 1}+\left(\frac{x_{m 2}-x_{m 1}}{2}\right)\right)-V \cdot t \\
y_{a c}=\left(y_{m 1}+\left(\frac{y_{m 2}-y_{m 1}}{2}\right)\right)-R
\end{gathered}
$$

The coordinates of the directing vector of straight line containing segment $M_{1} M_{2}$ will be equal to:

$$
\begin{aligned}
& x_{m 1 m 2}=x_{m 2}-x_{m 1} \\
& y_{m 1 m 2}=y_{m 2}-y_{m 1}
\end{aligned}
$$

Subsequently, length of segment $A C$ can be determined; it will be equal to:

$$
A C=\sqrt{\left(V t-x_{c}\right)^{2}+\left(R-y_{c}\right)^{2}}
$$




\section{Results and discussion}

Using the obtained dependencies (Eqs. 8-17), Eq. 7 will obtain the final form:

$$
\begin{aligned}
h & =\frac{\left(\left(x_{m 1}+\left(\frac{x_{m 2}-x_{m 1}}{2}\right)\right)-V \cdot t\right) \cdot\left(x_{m 2}-x_{m 1}\right)+\left(\left(y_{m 1}+\left(\frac{y_{m 2}-y_{m 1}}{2}\right)\right)-R\right) \cdot\left(y_{m 2}-y_{m 1}\right)}{\sqrt{\left(\left(x_{m 1}+\left(\frac{x_{m 2}-x_{m 1}}{2}\right)\right)-V \cdot t\right)^{2}+\left(\left(y_{m 1}+\left(\frac{y_{m 2}-y_{m 1}}{2}\right)\right)-R\right)^{2}}} . \\
& \frac{\sqrt{\left[V t-\left(x_{m 1}+\left(\frac{x_{m 2}-x_{m 1}}{2}\right)\right]^{2} \cdot\left[R-\left(y_{m 1}+\left(\frac{y_{m 2}-y_{m 1}}{2}\right)\right]^{2}\right.\right.}}{\sqrt{\left(x_{m 2}-x_{m 1}\right)^{2}+\left(y_{m 2}-y_{m 1}\right)^{2}}}
\end{aligned}
$$

Eq. 18 is, in fact, a mathematical model that allows one to make an assessment of the energy efficiency of the device work in terms of soil loosening and lifting of deep-seated table root crops.

Aforementioned methodology for the power determination was implemented as a computational model in the Octave 4.0 software environment. Additionally, specific soil stretching efforts were taken at the level of $6,700 \mathrm{~N} \cdot \mathrm{m}^{-2}$. As a result

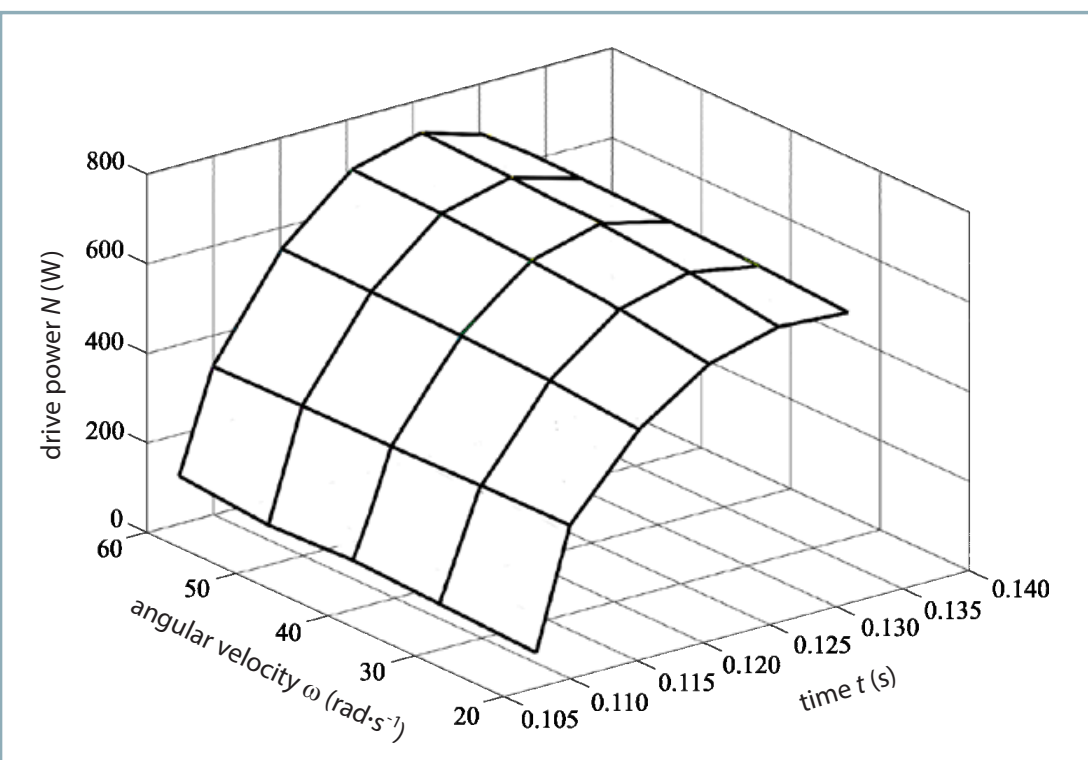

Fig. 5 Dependence of power $N$ consumed by the tooth as a function of time $t$ and rotor angular velocity $\omega$

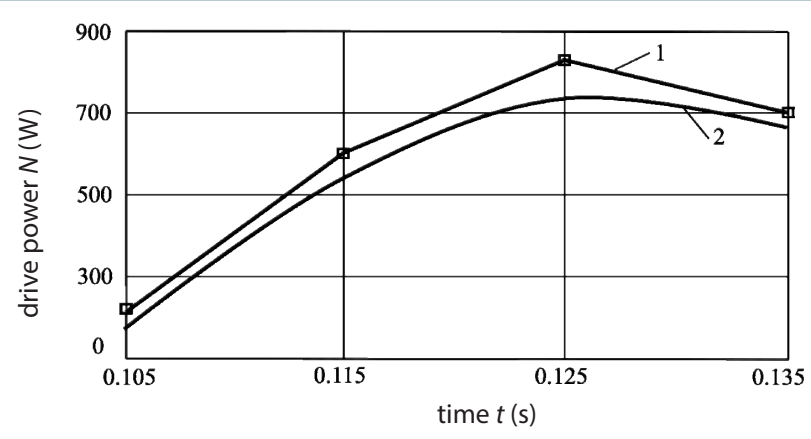

Fig. 6 Experimental and theoretical dependences of teeth power consumption $N$ on time $t$ at rotor angular speed $\omega=40 \mathrm{rad} \cdot \mathrm{s}^{-1}$

1 - experimental dependence; 2 - theoretical dependence of simulation, a response surface was constructed, which reflected the dependence of energy consumed by a rotor tooth at angular velocity $\omega$ and time $t$ from penetrating the soil to the tooth leaving it.

It is evident from Fig. 5 that with an increase in time, the power consumption increases, which is explained by an increase in the tooth soil penetration degree and, accordingly, the interaction area of its cutting surface. The decrease in power at the end, before the tooth leaves the working area, is due to a decreased soil reaction force upon the tooth. With increasing angular velocity, the power increases from 500 to $650 \mathrm{~W}$.

In order to test the theoretical model adequacy, an experiment was conducted to determine the power consumed by the working tool teeth. A graph of tooth power consumption $N$ dependent on time $t$ at a rotor angular speed $\omega=40$ $\mathrm{rad} \cdot \mathrm{s}^{-1}$ (Fig. 6) was obtained. Acquired experimental data were compared with the theoretical model. Statistical processing utilizing Fisher criterion showed that the theoretical model adequately describes the real process at a significance level of $5 \%$ (Dospehov, 2012). Nature of the dependence generally replicates the theoretical model, and differences observed in comparison to experimental data, skewing towards the larger side, can be explained by an unaccounted factor, i.e. friction force of the tooth lateral surface in contact with soil.

It is advisable to investigate the device power consumption case when several teeth interact with soil at the same time in the future. Moreover, it would be also worthy to pay attention to changes in power consumption depending on the inclination angle of tooth working area in relation to the radial direction. Therefore, aforementioned scientific tasks will become subjects of our further research.

\section{Conclusion}

This paper describes successful refined mathematical model for determining the energy consumption of the process of lifting of deepseated roots. Dependence of device power for soil loosening and lifting of deep-seated table root crops in 
the kinematic operational mode was established. It was found out that with an increase in the tooth penetration degree, the power consumption increases to a maximum of 500-600 W. Power decreases before the tooth leaves the soil, which can be explained by a decreased soil reaction force acting on tooth.

\section{References}

ANAR, M. - LIN, Z. - HOOGENBOOM, G. - SHELIA, V. - BATCHELOR, W. - TEBOH, J. - OSTLIE, M. - SCHATZ, B. - KHAN, M. 2019. Modelling growth development and yield of sugarbeet using DSSAT. In Agricultural Systems, vol. 169, pp. 58-70.

AULIN, V. - LYASYK, O. - TYKHYI, A. - KARPUSHIN, S. - DENYSIUK, N. 2018. Influence of rheological properties of a soil layer adjacent to the working body cutting element on the mechanism of soil cultivation. In Acta Technologica Agriculturae, vol. 21, no. 4, pp.153-159.

BULGAKOV, V. - BORIS, A. - IVANOVS, S. 2013. Mathematical model of interaction of operating element of top remover with head of root crop. In Engineering for Rural Development, Proceedings, vol. 12, pp. 115-120.

BULGAKOV, V. - IVANOVS, S. - ADAMCHUK, V. - BORIS, A. 2015 Mathematical model for determination of losses of sugar bearingmass when sugar beet tops are removed. In Engineering for Rural Development, Proceedings, vol. 14. pp. 41-45.

BULGAKOV, V. - IVANOVS, S. - RUZHYLO, Z. - GOLOVACH, I. 2016. Theoretical investigations in cleaning sugar beet heads from remnants of leaves by cleaning blade. In Engineering for Rural Development, vol. 15, pp. 1090-1097.
CHLOUPEK, O. - HRSTKOVA, P. - SCHWEIGERT, P. 2004. Yield and its stability, crop diversity, adaptability and response to climate change, weather and fertilisation over 75 years in the Czech Republic in comparison to some European countries. In Field Crops Research, vol. 85, no. 2-3, pp. 167-190.

DOSPEHOV, B. 2012. Methodology of field experiments. Moscow: Nauka, 352 pp. (In Russian: Metodika polevogo opyta).

FORMATO, A. - IANNIELO, D. - VILLECCO, F. - LENZA, T. - GUIDA, D. 2017. Design optimization of the plough working surface by computerized mathematical model. In Emirates Journal of Food and Agriculture, vol. 29, no. 1, pp. 36-44.

FOX, A. - PRATT, M. 1982. Computational geometry. Application in design and production. Moscow: Mir, $304 \mathrm{pp}$.

GAO, N. - ZHANG, D. - YANG, L. 2013. Mathematical modeling and simulation of an anti-blocking mechanism for no-till maize planter. In American Society of Agricultural and Biological Engineers Annual International Meeting 2013; Kansas City, UA, pp. 366-373.

PAVLOCKY, A. 2015. Energy-sufficient executive devices of agricultural mechanics: simulation and designing by means of a computer. In Mechanization and Electrification of Agriculture, vol. 101, no. 2, pp. 424-431.

PAVLOV, A. - KORABELJSKY, V. - PAVLOCKY, A. 1975. Geometrical substantiation of the surface shape, combining the rational cutting of the soil layer with its deformation. In Applied Geometry and Engineering Graphics, vol. 19, pp. 124-127.

RUCINS, A. - VILDE, A. 2005. Modelling forces acting on the plough body simulation in wider Europe. In $19^{\text {th }}$ European Conference on Modelling and Simulation, ECMS 2005, Riga, Latvia, pp. 425-430.

VILDE, A. - RUCINS, A. 2012. Development of agricultural mechanics. In Engineering for Rural Development, vol. 11, pp. 67-73. 